\title{
ANALYSIS OF FACTORS AFFECTING THERMAL COMFORT PROPERTIES OF WOVEN COMPRESSION BANDAGES
}

\author{
Abdelhamid R.R. Aboalasaad ${ }^{1 *}$, Z. Skenderi², Brigita Kolčavová S. ${ }^{1}$, Amany A.S. Khalil ${ }^{3}$ \\ 1 Department of Textile Technologies, Technical University of Liberec, Liberec 46117, Czechia \\ 2 Faculty of Textile Technology, University of Zagreb, 10000 Zagreb, Croatia \\ 3 Department of Textile Evaluation, Technical University of Liberec, Liberec 46117, Czechia \\ E-mail: eabdo6@gmail.com
}

\begin{abstract}
:
Compression bandage $(C B)$ as a porous material should provide both graduated pressure and thermal comfort properties to enable air permeability, heat transfer, and liquid perspiration out of the human body. The main factors affecting thermal comfort properties are the temperature difference between environment and skin, yarns' structure and material, fabric thickness, porosity, areal density, number of fabric layers, trapped air, and fabric structure. Thermal resistance $\left(R_{c t}\right)$ and water vapor resistance $\left(R_{e t}\right)$ are evaluated for four types of woven CBs. All bandage types were applied at the range of extension (10-80\%) using both two- and three-layer bandaging on thermal foot model (TFM). $R_{c t}$ values are compared with measured results by the Alambeta instrument, whereas $R_{\text {et }}$ test is performed on the Permetest device. Thermal resistance is significantly decreased when increasing the bandage extension from 10 to $40 \%$, then it is slightly increased by increasing the extension from 40 to $60 \%$, after that it is decreased especially at $80 \%$ extension due to lower bandage thickness and higher compression.
\end{abstract}

\section{Keywords:}

Thermal and water vapor resistance; $R_{c t}$ and $R_{e t}$; thermal foot model; extension; air permeability; bandage properties

\section{Introduction}

Clothing comfort is an important factor in the stage where people make their clothing selections [1]. Human thermal comfort is defined as a condition of mind, which expresses satisfaction with the surrounding environment. High temperatures and humidity provide discomfort sensations and sometimes heat stress (i.e., reducing the body's ability to cool itself). Moreover, discomfort and heat stress reduce productivity of workers and may lead to more serious health problems, especially for aged persons [2]. The thermal resistance of fabrics is a primary determinant of body heat loss in cold environments. Generally, high thermal resistance values of the clothing are required to maintain the body under thermal equilibrium conditions. In hot environments or at high activity levels, evaporation of sweat becomes an important avenue of body heat loss and fabrics must allow water vapor to escape in time to maintain the relative humidity between the skin and the first layer of clothing about $50 \%$ [2-5]. Perspiration is the process of losing body heat due to the moisture evaporation from the skin to the environment [6]. The warm-cool feeling is another parameter showing the thermal comfort. When the human touches a garment that has a different temperature than the skin, heat exchange occurs between the hand and fabric, so the warm-cool feeling is the first sensation. Which feeling is better depends on the customer; a cooler feeling is demanded for hot summer garments, whereas warmer feeling is preferred in winter [7].

Compression bandages (CBs) are produced with optimum stretch using highly twisted warp yarns such as cotton bandages, or elastomeric filament (elastane or spandex) with cotton or viscose, or using two or more yarns having different melting points as viscose-polyamide (V-PA) or cottonpolyamide-polyurethane (C-PA-PU) in which case bandage stretch and elasticity are given by steaming then heat setting. Medical CB (MCB) is designed to meet both the safety and the comfort of human beings, especially patients. MCB aims to provide graduated compression to the lower limb from the ankle to the knee to improve venous return, accelerate venous flow, reduce venous reflux by realignment of valves, improve venous pump action, and to reduce edema $[8,9]$.

\subsection{Important terms and definitions}

The heat energy can be transferred through the textile fabrics by conduction, convection and radiation as well as easily explainable phenomena such as heat exchange in porous media. The basic concepts of heat transfer through $\mathrm{CB}$ are explained as follows [10]:

"Thermal conductivity coefficient" $(\lambda)$ : heat transfer by conduction depends on the materials' heat conductivity, i.e., their capacity for transferring heat from a warmer medium to a cooler one. Conductivity coefficient $\lambda$ expressed in $\mathrm{W} / \mathrm{m}{ }^{\circ} \mathrm{C}$ or $\mathrm{W} \mathrm{m}^{-1}{ }^{\circ} \mathrm{C}^{-1}$ conveys the heat flow (Q) which is expressed in Watt, passing in $1 \mathrm{~h}$ through an area $(\mathrm{A})$ of $1 \mathrm{~m}^{2}$ of the fabric, having thickness $L$ at a temperature difference $\left(T_{m}-T_{a}\right)$ in ${ }^{\circ} \mathrm{C}$, as given in equation (1):

$$
\lambda=\frac{Q L}{\operatorname{At}\left(T_{m}-T_{a}\right)}
$$

However, the heat transfer coefficient $\mathrm{K}$ expressed in $\mathrm{W} / \mathrm{m}^{2} x^{\circ} \mathrm{C}$ conveys the heat flow passing during 1 hour through $1 \mathrm{~m}^{2}$ of 
fabric with actual thickness $L$ at the difference of temperatures of two media (air and fabric) $1^{\circ} \mathrm{C}$, as shown in equation (2):

$$
K=\frac{Q}{A t\left(T_{m}-T_{a}\right)}
$$

"Thermal resistance" $\left(R_{c t}\right)$ of textile fabrics is a function of the actual thickness of the material and its thermal conductivity $\lambda$. This function is given by equation (3), where $L$ is the actual thickness of the sample expressed in meter.

$$
\mathrm{R}_{\mathrm{ct}}=\mathrm{L} / \lambda \quad\left(\mathrm{m}^{2} \mathrm{~W}^{-1}{ }^{\circ} \mathrm{C}\right)
$$

"CLO value", the CLO is a unit of insulation, defined as the amount of insulation necessary to maintain comfort and a mean skin temperature of $33^{\circ} \mathrm{C}\left(92^{\circ} \mathrm{F}\right)$ in a room at $21^{\circ} \mathrm{C}\left(70^{\circ} \mathrm{F}\right)$ with air movement not over $3 \mathrm{~m} / \mathrm{min}$, relative humidity not over $50 \%$, with a metabolism of 50 calories $/ \mathrm{m}^{2} /$ hour. The CLO value is based upon human physiological factors as well as upon the engineering measurement of thermal characteristics. Lowest CLO value (0) is that of a nude person, highest practical CLO value (4) is that of Eskimo clothing (such as pants, coat, hood, and gloves). The Tog also describes the thermal resistance of clothing, $1 \mathrm{Tog}=0.645 \mathrm{CLO}$, and is equivalent in insulation to light summer clothing [11].

\subsection{Factors affecting testing of thermal properties}

The measurement of clothing insulation with thermal manikin is a dynamic balance adjustment process. It means that continuous adjustment of heat flux makes the manikin skin temperature approach a constant temperature gradually under the heat diffusion. The final state is that the manikin skin temperature is steady in a narrow range and very close to the constant temperature [12].

Through further adjustment and control, the skin temperature change of all parts approaches steadily the narrow range around the set temperature. The set balance range is $\pm 0.2^{\circ} \mathrm{C}$ around the constant temperature and is on the trend to reduce gradually. At the same time, the central temperature of the thermal manikin is getting closer to the set skin temperature. With all such essential conditions achieved, the system gets into the balance stage. After a while, we can calculate testing results according to all the balance parameters and print them out (Figure 1) [12].

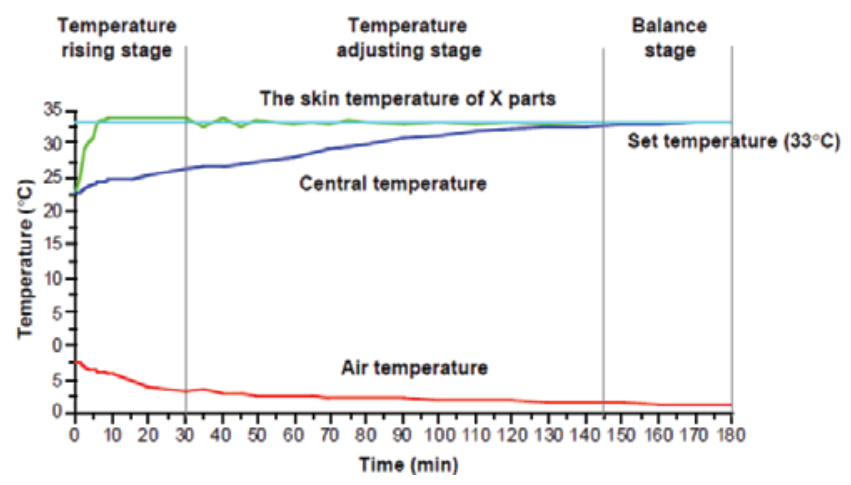

Figure 1. Skin temperature adjusting and control process of $X$ parts of thermal manikin [12]

\subsection{Effect of trapped air on thermal resistance of multilayer fabrics}

When people wear multilayer clothing ensembles under cold weather conditions or in hot environments, air spaces (air layer) are present between the skin and the inner layer or between two adjacent layers. These air spaces play a vital role in determining thermal properties of clothing. The thermal resistance of multilayer fabrics with air layers increased generally as the thickness of the air spaces increased up to a critical point. When the air layer thickness increased further above this point, the rate of increase in thermal resistance was slow owing to disturbance of convection and turbulence. This critical thickness was observed to be variable in different studies. Thus, including air spaces that are close to real life is an effective way to enhance thermal resistance of multilayer fabrics. More insulation per additional layer was obtained, when fabrics were assembled, a thin layer of air was enclosed between the layers, especially for fabrics with rough or irregular surfaces. Moreover, more insulation per additional layer could be ascribed to the fact that air spaces were between two layers, resulting in greater thermal resistance than the sum of single layers [10].

\subsection{Effect of pressure on heat transfer through multilayer fabrics}

CB is often worn under a pressure load, which is a significant factor in determining heat transfer properties of multilayer fabrics. O'Callaghan and Probert [13] tested the thermal resistance of one to eight layers of woven cotton, polyester, and nylon fabrics under various mechanical loads and indicated that the thermal resistance of fabric assemblies reduced with an increase in applied loading and that these decreases were relatively low as compared with changes resulting from varying the thickness. In addition, n-layers of fabrics provided less thermal resistance than a single layer of fabrics with the same thickness as n-layers of fabrics. Karunamoorthy and Das [14] developed a modified version of the guarded hot plate apparatus and measured the thermal resistance and conductivity of 20 different multilayer needle-punched nonwoven fabric assemblies under three levels of compression load $(700,1400$, and $2100 \mathrm{~Pa})$. The test results showed that the thermal conductivity of fabric assemblies was greater at the higher compression load due to a decrease in the volume of entrapped air.

Most of the researches on the thermal comfort properties performed either on knitted fabrics or nonwoven [15-19]. Many researchers have studied the effect of raw materials and knitted fabric construction parameters on the comfort behavior of fabrics. Investigations revealed that the type of fibers, fiber blends, yarn structure and its fineness, fabric structure, and different process parameters affect various comfort properties such as air permeability, moisture management, thermal conductivity, and thermal absorptivity [20-24].

So that it is necessary to test and analyze the thermal comfort properties of woven CBs, dealing with different yarn materials, fabric structures, thickness, porosity, weight per unit area, 
and number of bandage layers as a function of the applied compression during testing on thermal foot model (TFM), Permetest, and Alambeta testing devices.

\section{Experimental work}

\subsection{Materials}

Input materials for the creation of experimental woven $\mathrm{CB}$ samples were as follows: 1) $100 \%$ bleached cotton, 2) C-PA-PU, 3) V-PA, and 4) viscose-Lycra (V-L) bandages, as illustrated in Figure 2.

\subsection{Testing procedure}

\subsubsection{TFM description}

The measurement unit (MU) of foot manikin which is a part of original Thermal Sweating Foot Manikin System [25] was used for the measurement of thermal resistance only. The length of MU along $\mathrm{X}$-axis is $265 \mathrm{~mm}$, whereas along z-axis is $270 \mathrm{~mm}$. The unit consists of 13 segments all made of silver. There are 30 heaters on the $\mathrm{MU}$, from 2 to 4 for each segment, depending on the segment area. Each segment can be separately heated, turned off, or individually controlled by special software. The range of controlled temperature was set at $\pm 0.5^{\circ} \mathrm{C}$.

The main four types of CBs were wrapped on TFM at the range of extension (10-80\%) using both 50 and $66 \%$ overlap (i.e., two- and three-layer bandaging, respectively). Thermal resistance $\left(R_{c t}\right)$ was measured using TFM for all types of CBs as shown in Figure 2 [26]. Relative water vapor permeability and water vapor resistance $\left(R_{\text {et }}\right)$ were measured using the
Permetest instrument [27] according to ISO 11092 standard, at laboratory conditions (T: $22 \pm 2^{\circ} \mathrm{C}, \mathrm{RH}: 50 \pm 2 \%$ ), as shown in Figure 3 [28]. The obtained results of $R_{c t}$ were compared with Alambeta [29] testing device results as shown in Figure 4 [30]. All bandage samples were measured using Alambeta at initial porosity ( $0 \%$ extension) and (20-100\%) using special tensioning frame as shown in Figure 5 . Air permeability test was carried out using FX3300 air permeability tester according to ASTM D737 at working pressure of $100 \mathrm{~Pa}$ and $20 \mathrm{~cm}^{2}$ test area [31, 32].

\subsubsection{Adjusting the factors affecting $R_{c t}$ measurement on TFM}

The following steps are practical example to show how to adjust and stabilize the optimum conditions of TFM to test $R_{c t}$ of $C B$ (Figure 6). Segments 1 and 3 are kept off because CB effect usually starts after these segments and device door is opened. There are two types of testing (i.e., nude and clothed manikin) [12]. For clear comparison, mercerized cotton socks are used

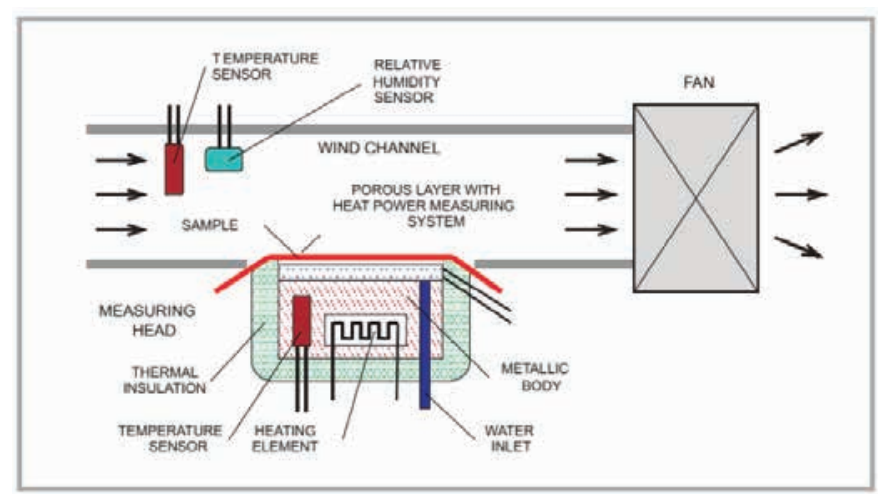

Figure 3. Permetest device for testing $\mathrm{R}_{\mathrm{et}}$ and $\mathrm{R}_{\mathrm{ct}}$ [28]

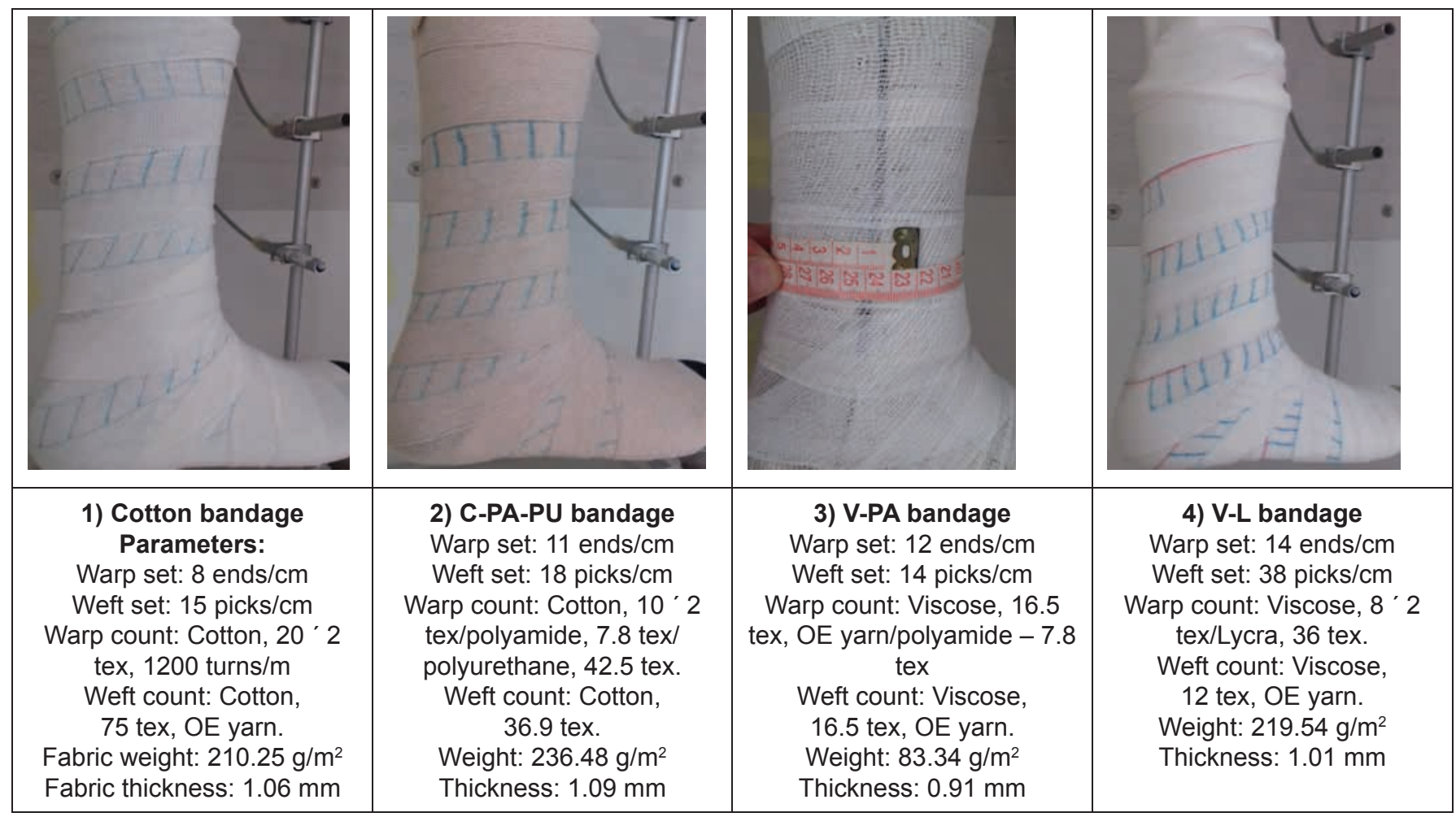

Figure 2. Woven CB samples on TFM and its characteristics

$\mathrm{CB}$, compression bandage; C-PA-PU, cotton-polyamide-polyurethane; TFM, thermal foot model; V-L, viscose-Lycra; V-PA, viscose-polyamide 


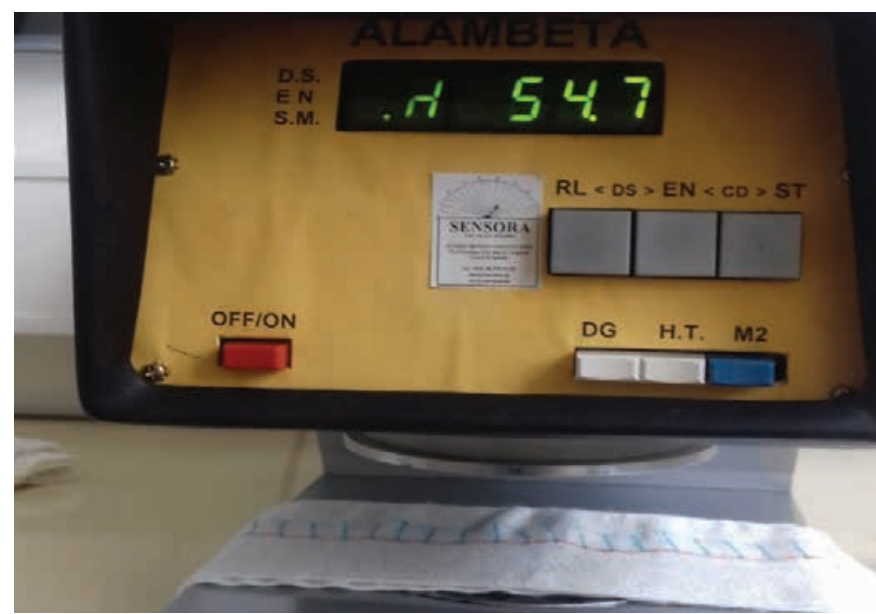

Figure 4. Alambeta testing device for thermal comfort properties [30]

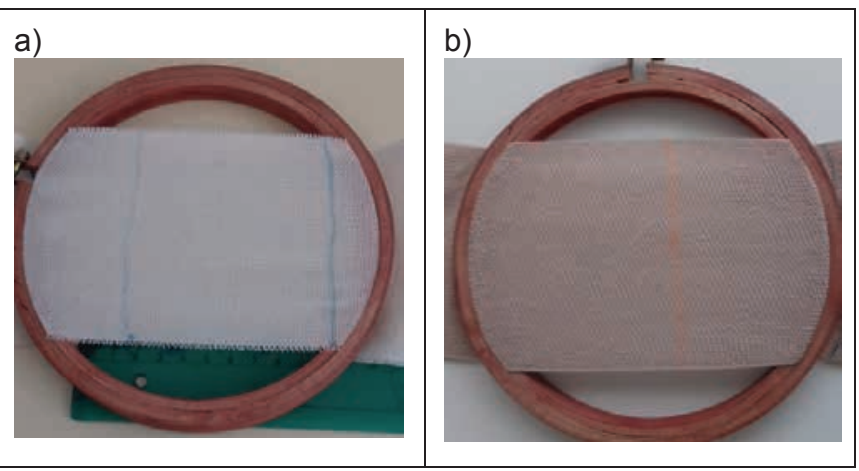

Figure 5. Stretching frame at $80 \%$ extension: a) cotton, b) C-PA-PU bandages C-PA-PU, cotton-polyamide-polyurethane

to cover TFM as underwear for all measured samples to ensure more stabilization and steady conditions as shown in Figure 7.

The stabilization process continues till the device reads the standard ambient conditions ( $\mathrm{T}: 20 \pm 2^{\circ} \mathrm{C}, \mathrm{RH}: 50 \pm 5 \%$ ), after that the measurement of the initial thermal resistance $\left(R_{c t 0}\right)$, then stabilization (waiting for 20 min) while wearing CB sample over socks. Finally, $R_{c t}$ values can be measured using the measured $\mathrm{R}_{\mathrm{ct0}}$ as a reference value (Figure 8 and equation 4) [5].

$R_{c t}=\frac{A \cdot\left(T_{s}-T_{a}\right)}{H}-R_{c t 0}$

$$
R_{e t}=\frac{A \cdot\left(p_{s}-p_{a}\right)}{H}
$$

where $R_{c t}$ is the dry resistance of sample only $\left(m^{2 \circ} \mathrm{C} / \mathrm{W}\right), T_{\mathrm{s}}$ is the hot plate surface temperature $\left({ }^{\circ} \mathrm{C}\right), \mathrm{T}_{\mathrm{a}}$ is the ambient temperature $\left({ }^{\circ} \mathrm{C}\right), \mathrm{H} / \mathrm{A}$ is the zone heat flux $\left(\mathrm{W} / \mathrm{m}^{2}\right), \mathrm{R}_{\mathrm{ct} 0}$ is the clothed TFM dry resistance $\left(\mathrm{m}^{2 \circ} \mathrm{C} / \mathrm{W}\right) . \mathrm{R}_{\text {et }}$ is the evaporative resistance of sample only $\left(\mathrm{m}^{2} \mathrm{~Pa} / \mathrm{W}\right), \mathrm{p}_{\mathrm{s}}$ is the saturation vapor pressure at hot plate surface $(\mathrm{Pa})$, and $\mathrm{p}_{\mathrm{a}}$ is the ambient partial vapor pressure $(\mathrm{Pa})$.

\section{Results and discussions}

\subsection{Effect of bandage extension and number of layers on thermal resistance}

For comparison, all bandage types were wrapped on TFM at the same extension levels that range from 10 to $80 \%$ using both two- and three-layer bandaging. Figures 9 and 10 illustrate that thermal resistance $\left(R_{c t}\right)$ is significantly decreased by increasing the bandage extension from 10 to $40 \%$ due to the decrease in total thickness of layers. Then, $R_{c t}$ is slightly increased by increasing the extension from 40 to $60 \%$ that may be due to the higher porosity of bandages $(0.364,0.306,0.471$, and 0.325 for cotton, C-PA-PU, V-PA, and V-L bandages, respectively) $[33,34]$. Moreover, it is illustrated that cotton bandage has the lowest $R_{c t}$ values due to yarns' material and structure. This may be due to higher moister regain of cotton $(8.5 \%)$ and viscose $(11-12 \%)$ compared with polyamide (4-4.5\%) and polyurethane $(0.3-1.2 \%)$, which decreases the thermal resistance of cotton and viscose bandages [35-37]. After that, $R_{c t}$ values are decreasing for all samples, especially at $80 \%$ extension. The most significant factors for this decrease are the lower bandage thickness and higher compression values.

As many factors can affect the thermal resistance measurements, it was necessary to measure $R_{c t 0}$ before each measurement using clothed TFM. There is $R_{c t 0}$ for each $R_{c t}$ measurement to get the precise $R_{c t}$ values of CB and simultaneously to monitor deviations of $R_{c t 0}$ values. The actual

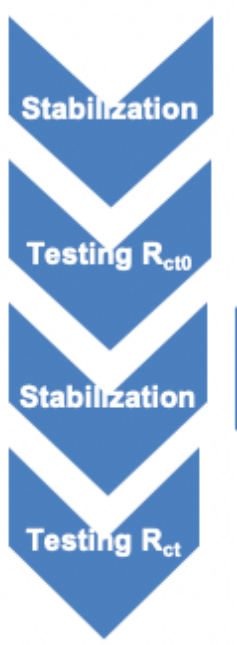

- Stabilization of TFM with mercerized cotton socks

-Acheive the stabilization (T: $20 \pm 2{ }^{\circ} \mathrm{C}, \mathrm{RH}: 50 \pm 5 \%$ ), waiting

time dependes on the ambient conditions.

- After reaching steady state conditions ( $\mathrm{T}: 20 \pm 2{ }^{\circ} \mathrm{C}, \mathrm{RH}: 50 \pm 5 \%$ ).

- Measuring the $\mathrm{R}_{\text {cto }}$ on clothed TFM.

-Stabilization while wearing the CB sample over the mercerized socks.

-Waiting for $20 \mathrm{~min}$ to reach the steady state of heat flow through the sample.

- Measuring $\mathrm{R}_{\mathrm{ct}}$ while wearing $\mathrm{CB}$ sample over the socks then recording the average measured $R_{c t}$ values.

Figure 6. Optimum testing procedure of measuring $R_{c t}$ on TFM. TFM, thermal foot model 


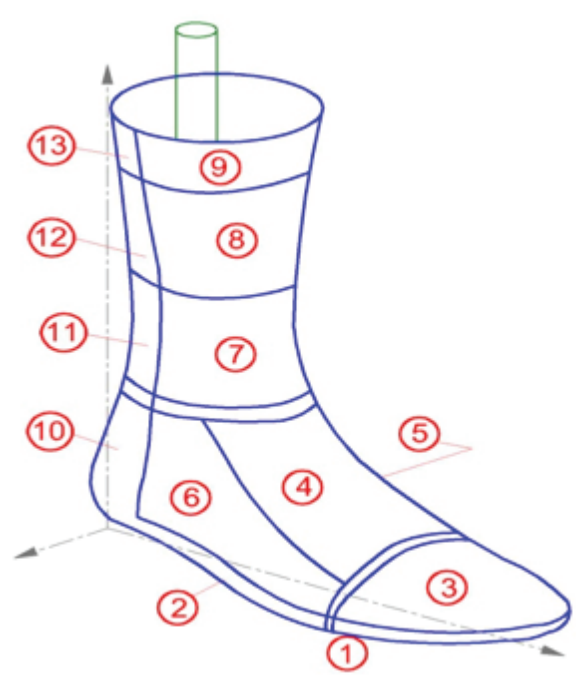

(a)

\begin{tabular}{|c|c|c|c|c|}
\hline Kanali & SetT & Temp & Snaga & \\
\hline 1. Prsti & 35.0 & 30,17 & 0.00 & $00<$ \\
\hline 2 & 35,0 & 34.96 & 1.88 & $00<$ \\
\hline 3 & 35,0 & 28,16 & 0.00 & $00<$ \\
\hline 4 & 35,0 & 34,96 & 0,89 & $100<$ \\
\hline 5 & 35.0 & 35.02 & 0.60 & 000 \\
\hline 6 & 35,0 & 34,97 & 0.65 & 000 \\
\hline 7 & 35,0 & 34,99 & 0,99 & 000 \\
\hline 8 & 35.0 & 34,95 & 0,75 & 000 \\
\hline 9 & 35.0 & 34,97 & 1.02 & 000 \\
\hline 10 & 35,0 & 34,97 & 1,39 & $00 \bigcirc$ \\
\hline 11 & 35,0 & 34,95 & 0.88 & $00 C$ \\
\hline 12 & 35,0 & 35,06 & 1,10 & 000 \\
\hline \multirow[t]{2}{*}{13} & 35,0 & 34,92 & 0.62 & 000 \\
\hline & 35.0 & \begin{tabular}{|l|} 
Set \\
\end{tabular} & & Sve ON \\
\hline
\end{tabular}

(b)

Figure 7. (a) Segments of TFM and (b) reached steady state condition TFM, thermal foot model

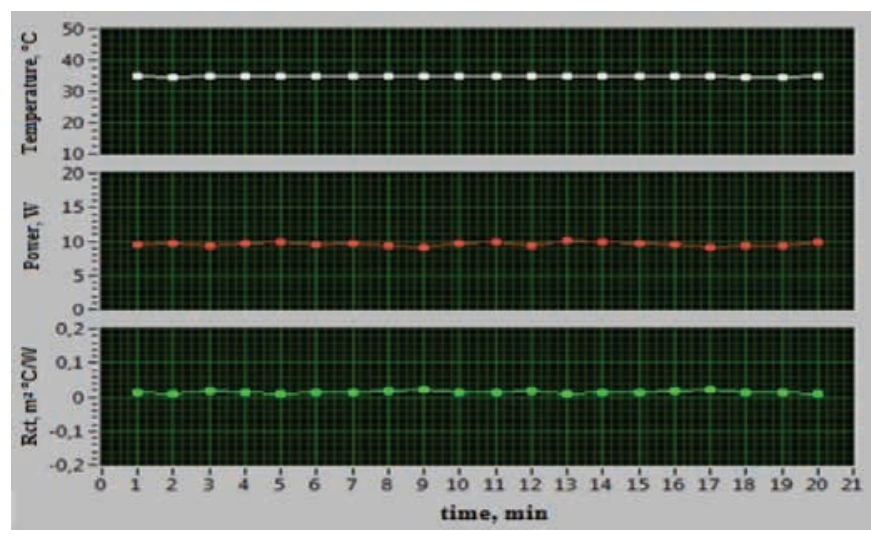

Figure 8. Measuring $R_{c t}$ while wearing $C B$ over socks $\mathrm{CB}$, compression bandage

values of $R_{c t}$ can be calculated directly by the device software adding measured $R_{c t 0}$ as reference value. Moreover, the obtained $R_{c t}$ values could enable for clear comparison between different bandage samples as illustrated by equation (6).

$$
R_{c t(F)}=R_{c t(\text { all })}-R_{c t 0}
$$

where $R_{c t(F)}$ is the net thermal resistance of the bandage sample (two or three layers), $\mathrm{R}_{\mathrm{ct}(\text { all) }}$ is the total thermal resistance of the bandage sample + one layer of mercerized socks as clothed $T F M$, and $R_{\text {cto }}$ is the initial thermal resistance of the clothed TFM wearing mercerized socks only.

\subsection{Relationship between applied tension and thermal resistance}

While increasing the applied bandage tension from 0.5 to $10 \mathrm{~N}$, the thermal resistance is decreasing. These results declare the effect of increasing the bandage compression and decreasing fabric thickness at higher values of extension. Moreover, the bandage porosity is increasing based on the increase in bandage tension. The same behavior for three layers, but the additional effect of third layer, is lower than the first and second layers as shown in Figures 11 and 12. This is attributed to the fact that the thermal resistance of the multilayer fabrics

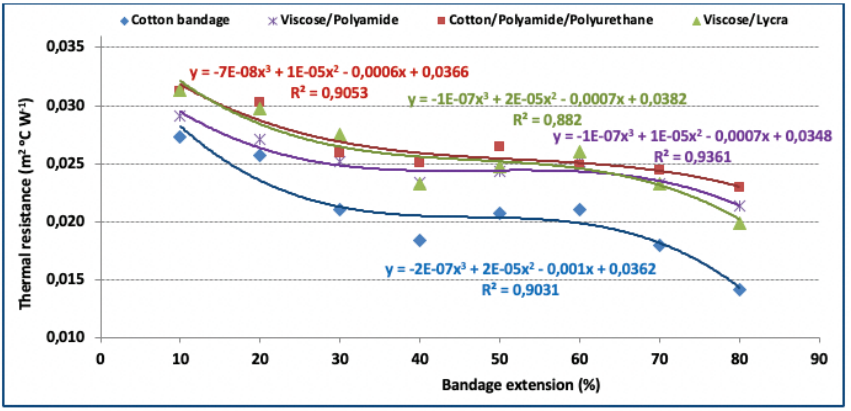

Figure 9. Effect of bandage extension on thermal resistance of twolayer $\mathrm{CB}$.

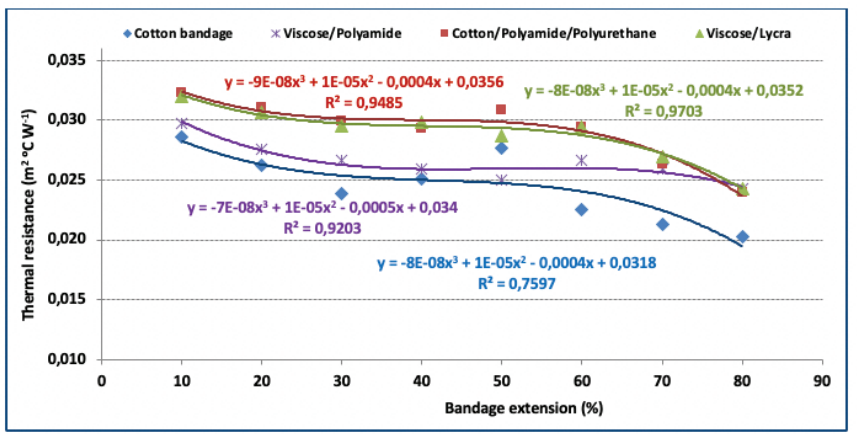

Figure 10. Effect of bandage extension on thermal resistance of threelayer $\mathrm{CB}$

decreases under higher load values or due to the compression between layers.

\subsection{Effect of total thickness of layers on thermal resistance}

However, the bandages are wrapped on TFM at extension level ranged from 10 to $80 \%$ using both $50 \%$ and $66 \%$ overlap. The total thicknesses of bandage layers at $10 \%$ extension are 2.04 , $2.15,1.53$, and $2.07 \mathrm{~mm}$. These values are decreasing at $80 \%$ to be $1.04,1.11,0.76$, and $1.08 \mathrm{~mm}$ for cotton, C-PA-PU, V-PA, and $\mathrm{V}-\mathrm{L}$ bandages, respectively. So that thermal resistance is decreasing by the decrease in total bandage thicknesses for both two- and three-layer bandaging, as shown in Figures 13 


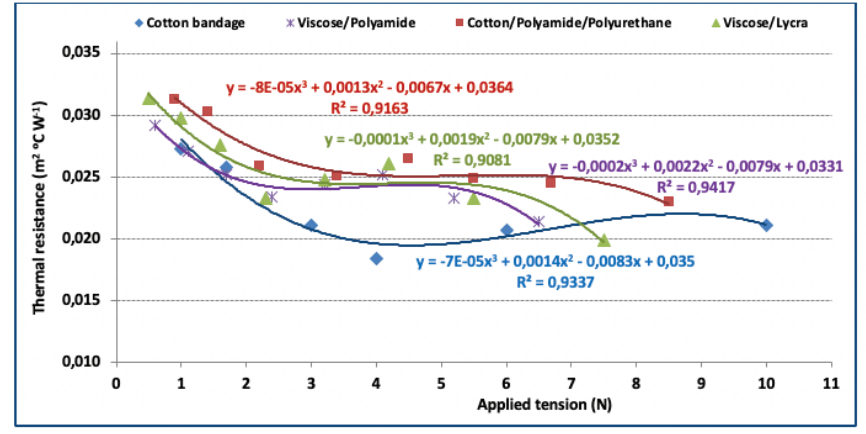

Figure 11. Effect of applied tension on thermal resistance of two-layer $\mathrm{CB}$.

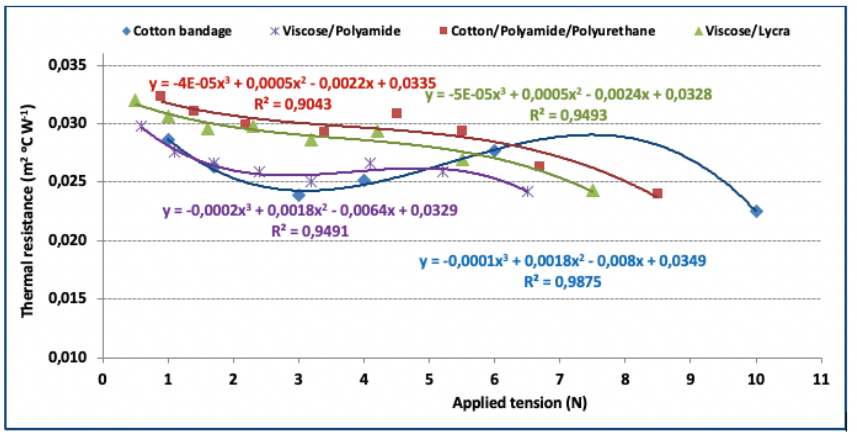

Figure 12. Effect of applied tension on thermal resistance of threelayer $\mathrm{CB}$.

and 14, respectively. The reduction percentage of $R_{c t}$ results due to extension $10-80 \%$ are $48.09,26.63,26.73$, and $36.66 \%$ for cotton, C-PA-PU, V-PA, and V-L bandages, respectively, using two layers while the reduction effect was lower for three layers as $29.37,25.77,18.52$, and $24.08 \%$, respectively.

\subsection{Effect of bandage extension on thermal conductivity and resistivity}

Alambeta testing device was used to test thermal conductivity and resistivity for all bandage samples at initial porosity $(0 \%$ extension) and (20-100\% extension) using two layers during testing. Figure 15 concludes the thermal conductivity values for cotton, C-PA-PU, V-PA, and V-L bandages as 0.06815 , $0.05337,0.05648$, and $0.05921\left(\mathrm{~W} \mathrm{~m}^{-1} \mathrm{~K}^{-1}\right)$, at $0 \%$ extension, whereas the conductivity decreases at $100 \%$ to 0.04705 , $0.03573,0.03781$, and 0.04424 , respectively. This decrease may be due to the decrease in bandage thickness and higher porosity values when increasing the bandage extension to $100 \%$. As for the thermal resistance, Figure 16 illustrates that $R_{c t}$ is proportionally increasing with bandage extension. The $R_{c t}$ values at $0 \%$ extension are $0.02078,0.03215,0.03149$, and

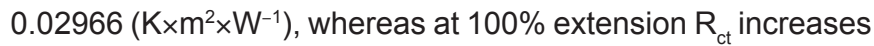
to $0.02419,0.03579,0.03486$, and 0.03144 for cotton, C-PAPU, V-PA, and V-L bandages, respectively.

There is a bit deviation between Alambeta and TFM testing results of $\mathrm{CBs}$, because the compression effect for both twoand three-layer bandaging is more significant when using the TFM model, as concluded in Figure 16. Moreover, Alambeta testing is performed on planner fabric not simulating the real bandage wrapping. So that according to TFM, the $R_{c t}$ values are decreasing as the bandage extension increases from 10 to $80 \%$ due to the significant increase in bandage tension.

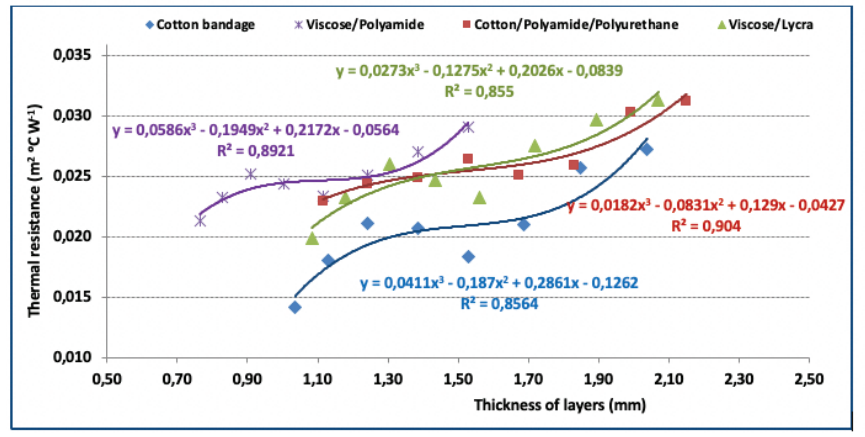

Figure 13. Effect of layer thickness on thermal resistance of two-layer CB

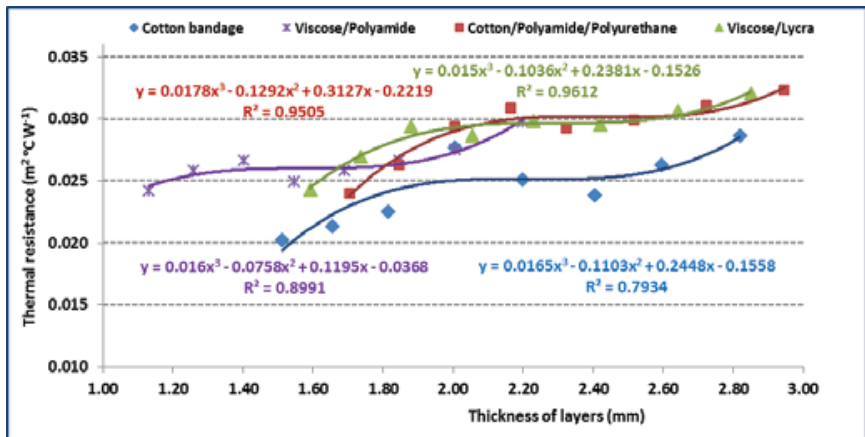

Figure 14. Effect of layer thickness on thermal resistance of three-layer CB.

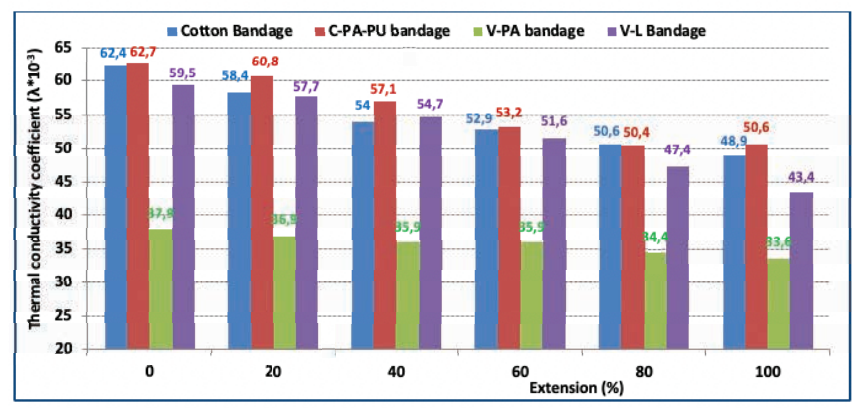

Figure 15. Effect of bandage extension on thermal conductivity coefficient

\subsection{Effect of bandage extension on water vapor resistance}

Water vapor permeability is the ability to transmit vapor out of the body, and it can be calculated theoretically by equation (5). If the moisture resistance is too high to transmit heat, by the transport of mass and at the same time the thermal resistance of the textile layers considered by us is high, the stored heat in the body cannot be dissipated and causes an uncomfortable sensation [38].

Water vapor resistance for all bandages was measured using Permetest device at $0 \%$ extension, and $10-80 \%$ extension for two-layer bandaging. Obtained results confirm that the $R_{\text {et }}$ is decreasing while increasing the bandage extension to $20 \%$ then it is improving till $60 \%$ then it is significantly decreasing at $80 \%$ extension, as indicated in Figure 17 . However, the testing on Permetest is fast, easy, and nondestructive, but it is not exactly simulating the required testing method of $R_{\text {et }}$ for $C B s$ as compared with TFM in which case the compression influence and air layer between each two adjacent bandage layers are more significant factors. 


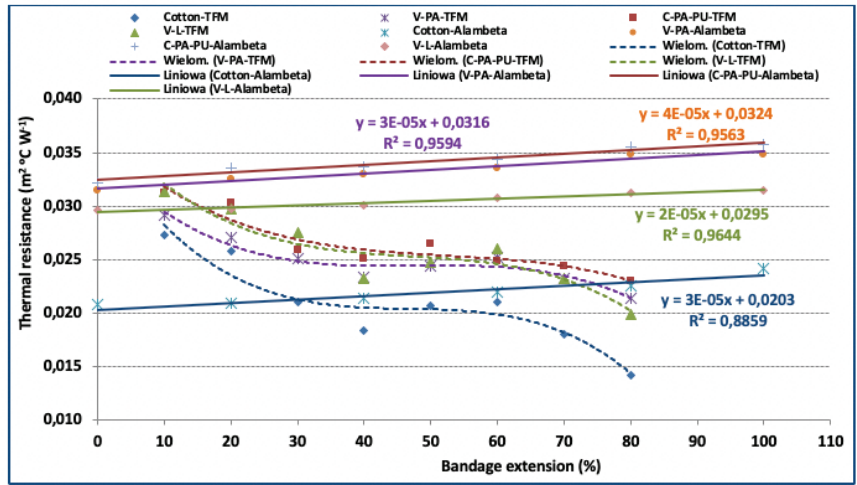

Figure 16. Comparison between $\mathrm{R}_{\mathrm{ct}}$ values on TFM and Alambeta, two layers. TFM, thermal foot model

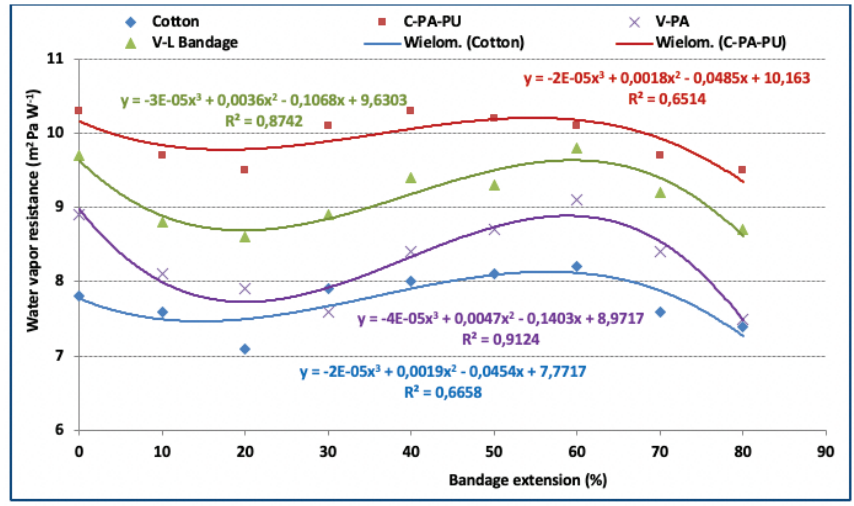

Figure 17. Effect of bandage extension on water vapor resistance

\subsection{Effect of bandage extension on air permeability}

Air permeability test was performed for all bandage samples at initial porosity of $0 \%$ extension and $10-100 \%$ extension using two layers for testing. The obtained results confirmed that the air permeability values of all CBs are significantly improved when increasing the bandage extension at the range of $0-100 \%$. Figure 18 emphasizes that V-PA bandage has the highest air permeability due to higher porosity and lower areal density $\left(83.34 \mathrm{~g} / \mathrm{m}^{2}\right)$ compared with other bandages, as illustrated in Figure 2.

\section{Conclusion}

Four main types of woven CBs were used for testing the $R_{c t}$ and $R_{\text {et }}$ of CB on the TFM and Permetest devices, respectively. TFM enabled bandage application under tension and provided a valuable insight into heat distribution across the entire ensemble under simulated wear conditions. The main factors affecting thermal comfort properties were discussed and analyzed. According to TFM, $R_{c t}$ values were significantly decreasing by increasing the bandage extension from 10 to $40 \%$ due to the decrease in fabric thickness. Then, it was slightly increasing from 40 to $60 \%$ extension that may be due to the higher porosity of bandages (i.e., 0.364, 0.306, 0.471, and 0.325 for cotton, C-PA-PU, V-PA, and V-L bandages, respectively) and optimum bandage thickness and air layer. After that, $R_{c t}$ was decreasing, especially at $80 \%$ extension due to lower bandage thickness and higher applied tension. The compression effect was more significant when using the

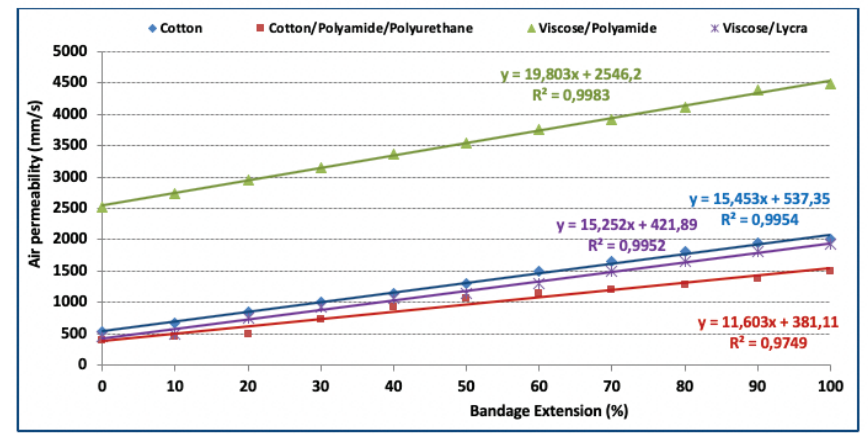

Figure 18. Effect of bandage extension on air permeability, two layers

TFM compared with Alambeta in which the testing samples are in planner form and noncompressed. The obtained results by Permetest confirmed that the $R_{\text {et }}$ was decreasing while increasing the extension to $20 \%$ then it was slightly increasing at $20-60 \%$, after that it was significantly decreasing at $80 \%$ extension due to lower thickness and little amount of trapped air between fabric layers. Results ensured that the air permeability of all CBs was significantly improving when increasing the bandage extension at the range of $0-100 \%$.

\section{Acknowledgments}

This work is supported by Student Grant Scheme (SGS 21249), Technical University of Liberec, Czech Republic. I would like to acknowledge the assistance and cooperation of my colleagues (Emilija Zdraveva, Dora Hranilović, and Tariq Mansoor), especially during testing of my samples.

\section{References}

[1] Utkun, E. (2015). A research on various comfort properties of interlock knitted fabrics. Industria Textila, 66(1).

[2] Huang, J. (2016). Review of heat and water vapor transfer through multilayer fabrics. Textile Research Journal, 86(3), 325-336

[3] Ghosh, A., Mal, P., Majumdar, A., Banerjee, D. (2017). An investigation on air and thermal transmission through knitted fabric structures using the Taguchi method. Autex Research Journal, 17(2), 152-163. DOI: 10.1515/aut2016-0009.

[4] Qian, X., Fan, J. (2009). A quasi-physical model for predicting the thermal insulation and moisture vapour resistance of clothing. Applied Ergonomics, 40(4), 577590.

[5] Salopek, C. I., Skenderi, Z. (2010). Approach to the prediction of thermophysiological comfort, Chapter 09 in DAAAM International Scientific Book 2010, pp. 081-088, B. Katalinic (Ed.). DOI: 10.2507/daaam.scibook.2010.09.

[6] Bizjak M., Gorjanc D. (2014). The influence of increased elasticity on resistance of cotton fabrics. XIIIth International Izmir Textile and Apparel, April 2-5

[7] Çolak, S. M., et al. (2016). Thermophysiological comfort properties of the leathers processed with different tanning agents. Journal of Textile and Apparel/Tekstil ve Konfeksiyon, 26(4), 436-443. 
[8] Nelson, E. A., Hillman, A., Thomas, K. (2014). Intermittent pneumatic compression for treating venous leg ulcers. Cochrane Database of Systematic Reviews, (5). Art. No.: CD001899. DOI: 10.1002/14651858.CD001899.pub4.

[9] Agale, S. V. (2013). Chronic leg ulcers: epidemiology, aetiopathogenesis, and management. Ulcers, Hindawi Publishing Corporation, 2013 Ulcers, Article ID 413604. http://dx.doi.org/10.1155/2013/413604.

[10] Abdel-Rehim, Z. S., Saad, M. M., El-Shakankery, M., Hanafy, I. (2006). Textile fabrics as thermal insulators. AUTEX Research Journal, 6(3), 148-161.

[11] Bairagi S., et al. (2016). Study on potential application of natural fibre made fabrics as thermal insulation medium, American International Journal of Research in Science, 16-203.

[12] Nilsson, H., Holmér, I. (2000). Proceedings of the Third International Meeting on Thermal Manikin Testing, 3IMM, at the National Institute for Working Life, October 12-13, 1999. www.niwl.se/ah/nr2000:4.

[13] O'Callaghan, P. W., Probert, S. D. (1977). Thermal resistance behaviour of single and multiple layers of clothing fabrics under mechanical load. Applied Energy, 3(1), 3-12.

[14] Karunamoorthy S., Das A. (2014). Study on thermal resistance of multilayered fabrics under different compressional loads. The Journal of The Textile Institute, 105(5), 538-546.

[15] Srdjak, M., Skenderi, Z., Cubric, I. S. (2009). Water vapor resistance of knitted fabrics under different environmental conditions. Fibres and Textiles in Eastern Europe, 17(2), 72-75.

[16] Kotb, N. A., et al. (2011). Quality of summer knitted fabrics produced from microfiber/cotton yarns. Journal of Basic and Applied Scientific Research, 1(12), 3416-3423.

[17] Ramachandran, T., Manomani, G., Vigneswaran, C., (2010). Thermal behavior of ring - and compact - spun yarn single jersey, rib and interlock knitted fabrics. Indian Journal of Fibre and Textile Research, 35, 250-257.

[18] Oğlakcioğlu, N., Marmarali, A. (2007). Thermal comfort properties of some knitted structures. Fibres and Textiles in Eastern Europe, 15(5-6), 64-65.

[19] Hes, L., (1987). Thermal Properties of Nonwovens. Proceedings of Congress Index 87, Geneva.

[20] Chidambaram, P., Govind, R., Venkataraman, K. C., (2011). The effect of loop length and yarn linear density on the thermal properties of bamboo knitted fabric. AUTEX Research Journal, 11(4), 102-105.

[21] Ogulata, R. T., Mavruz, S. (2010). Investigation of porosity and air permeability values of plain knitted fabrics. Fibres and Textiles in Eastern Europe, 18, 71-75.

[22] Onofrei, E., Rocha, A. M., Catarino, A. (2011). The influence of knitted fabrics' structure on the thermal and moisture management properties. Journal of Engineered Fibres and Fabrics, 6(4), 10-22.
[23] Ramakrishnan, G., Dhurai, B., Mukhopadhyay, S. (2009). An investigation into the properties of knitted fabrics made from viscose microfibres. Journal of Textile and Apparel, Technology and Management, 6(1), 1-9.

[24] Cubric, I. S., Skenderi, Z., et al. (2012). Experimental study of thermal resistance of knitted fabrics. Experimental Thermal and Fluid Science, 38, 223-228.

[25] Foot Manikin Technical Specification for model FM 005-08, Version 1.0, March 2010, UCS d.o.o., Slovenia.

[26] Mekjavic, I. B., et al. (2005). Static and dynamic evaluation of biophysical properties of footwear: the Jozef Stefan institute sweating thermal foot manikin system. In Prevention of Cold Injuries (pp. 6-1 - 6-8). Meeting Proceedings RTO-MP-HFM-126, Paper 6.

[27] SENSORA INSTRUMENTS \& CONSULTING, REG. No. 183306 81, VAT No. CZ440128092 Na Výbezku 312, 460 15 LIBEREC, Czech Republic. http://www.sensora.eu/ PermetestManual09.pdf .

[28] Bogusławska-Bączek, M., Hes, L. (2013). Effective water vapour permeability of wet wool fabric and blended fabrics. Fibres and Textiles in Eastern Europe.

[29] Hes L. (2008). Non-destructive determination of comfort parameters during marketing of functional garments and clothing. Indian Journal of Fibre and Textile Research, 33, 239-245.

[30] Hes L. Catalogues of the ALAMBETA and PERMETEST instruments, SENSORA Co. (Czech Republic).

[31] Havlová M. (2014). Model of vertical porosity occurring in woven fabrics and its effect on air permeability. Fibres and Textiles in Eastern Europe, 22, 58-63.

[32] ASTM D737:96. Standard Test Method for Air Permeability of Textile Fabrics.

[33] Bhattacharjee, D., Kothari, V. K. (2008). Prediction of thermal resistance of woven fabrics. Part II: heat transfer in natural and forced convective environments. Journal of the Textile Institute, 99(5), 433-449.

[34] Mao, N., Russell, S. J. (2007). The thermal insulation properties of spacer fabrics with a mechanically integrated wool fiber surface. Textile Research Journal, 77(12), 914922.

[35] Gokarneshan, N. (2018). Some significant developments in bandage fabrics. Journal of Nursing and Patient Health Care, 1(1), 105.

[36] Kumar, B., Das, A., Alagirusamy, R. (2014). Effect of material and structure of compression bandage on interface pressure variation over time. Phlebology, 29(6), 376-385.

[37] Ding, D., Tang, T., Song, G., McDonald, A. (2011). Characterizing the performance of a single-layer fabric system through a heat and mass transfer model-Part II: thermal and evaporative resistances. Textile Research Journal, 81(9), 945-958.

[38] Oğlakcioğlu, N., Marmarali, A. (2007). Thermal comfort properties of some knitted structures. Fibres and Textiles in Eastern Europe, 15(5-6), 64-65. 